\title{
Primary pleural haemangioendothelioma in an Italian female patient: a case report and review of the literature
}

\author{
M. Bocchino1, E. Barra2, F. Lassandro3, F. Ranieri4, \\ R. Muto 3 , G. Rea ${ }^{3}$
}

\begin{abstract}
Primary pleural haemangioendothelioma in an Italian female patient: a case report and review of the literature. M. Bocchino, E. Barra, F. Lassandro, F. Ranieri, R. Muto, G. Rea.

Primary epithelioid haemangioendothelioma (EHE) of the pleura is a rare vascular tumour that occurs mainly in men. Pleural effusion and thickening are the most common clinical presentations. A 58 year old female, nonsmoking patient presented to us with dry cough, dyspnoea and left chest pain for several weeks (no asbestos exposure). Standard chest $\mathrm{X}$-ray and contrast enhanced multislice computed tomography revealed a large-size lobulated mass originating from the pleura which was diagnosed
\end{abstract}

\begin{abstract}
as primary pleural haemangioendothelioma (PHE) by histology and immunohistochemistry (reactivity for vimentin, CD31, CD34, Factor VIII and ulex europeaus). No metastases were detected. The patient refused treatment and died three months later due to the onset of acute and progressive respiratory failure. Despite the lack of highgrade malignancy, primary PHE displays a poor prognosis while curative therapies are actually not available. To our knowledge, this is the first case of primary PHE in a female patient occurring in Italy and the third one to have been reported in English literature. Difficulties in diagnosis and treatment management are discussed below. Monaldi Arch Chest Dis 2010; 73: 3, 135-139.
\end{abstract}

Keywords: Haemangioendothelioma, Immunohistochemistry, Pleura.

1 Department of Clinical and Experimental Medicine, "Federico II" University, Naples,

2 Department of Pathology, Monaldi Hospital, Naples,

3 Department of Radiology, Monaldi Hospital, Naples,

4 Department of Radiology "Magrassi-Lanzara”, Second University of Naples, Naples, Italy.

Correspondence: Marialuisa Bocchino, MD, PhD, Department of Clinical and Experimental Medicine, Respiratory Medicine Section, Via S. Pansini 5, 80131 Naples, Italy; e-mail: marialuisa.bocchino@unina.it

\section{Introduction}

Epithelioid haemangioendothelioma (EHE) is a rare malignant vascular tumour of unknown aetiology with an intermediate aggressiveness between haemangioma and angiosarcoma. It can arise in any organ, but is most often found in the liver and lung. Primary pulmonary EHE was first described in 1975 by Dail and Leibow and initially termed "intravascular bronchioloalveolar tumour (IVBAT)" due to its epithelioid morphology and propensity for vascular invasion [1]. Pulmonary EHE has a chronic clinical course, the longest survivor being a female patient who died from pneumonia 24 years after the onset of the disease. In 1998, Kitaichi et al. reported a series of 21 patients affected by primary pulmonary EHE recruited in Asia [2]. Mean age at diagnosis or upon the onset of the symptoms was 44 years: males were detected more frequently than females by symptoms, including cough, dyspnoea and chest pain. Fifteen cases showed bilateral multiple nodular opacities. Partial spontaneous regression was demonstrated in three cases. Concomitance of pleural effusion was associated with a poor prognosis. A further series of 11 cases of lung
EHEs have been described most recently in Germany [3], two cases with different clinical outcomes have been reported in France [4] and two further patients with unusual high resolution CT findings have been described in Japan [5].

Unlike the lung counterpart, EHE primarily originating from the pleura (PEH) is quite an uncommon event. PEHs have been described as isolated reports and small series. All except 2 cases occurred in men aged from 34 to 71 yrs. Pleural effusions and thickening are the most common clinical presentations. Despite the lack of high-grade malignancy, $\mathrm{PEH}$ is associated with a poor prognosis resulting in death in the majority of cases while curative therapies are not actually available $[6,7]$. It usually mimics mesothelioma or adenocarcinoma. Distinguishing EHE from epithelioid angiosarcoma is also an issue of concern. Exposure to asbestos and smoking are unproven risk factors.

Herein we describe a case of primary PEH occurring in a female patient. To our knowledge, this is the third report to have been made in English and the first in Italy. Difficulties in diagnosis and treatment management of primary PEH are discussed. 


\section{Case report}

A 58-yr old Caucasian female was admitted to the hospital due to dry cough, progressive dyspnoea on exertion and left chest pain for several weeks. The patient referred to have been treated with inhaled bronchodilators with no benefit. Past medical history was significant for epilepsy since the age of 15 year currently under daily treatment with carbamazepine. She had no history of smoking or of occupational exposure to asbestos. Physical examination revealed a significantly decreased expansion of the left hemithorax which was associated with dullness on percussion and hypoventilation. Analysis of arterial blood gases was within the normal range when the patient was breathing ambient air at rest. Oxygen desaturation was instead revealed on exercise. Spirometry was not performed as the patient was not compliant. Routine laboratory findings were unremarkable. A standard chest X-ray showed an extensive mixed opacity in the upper and middle sides of the left hemithorax with associated areas of pleural thickening (figure 1A). A multidetector computed tomography scan of the thorax showed a moderately sized pleural effusion on the left upper side. There was also pleural thickening which became a nodular mass up to $12 \mathrm{~cm}$ in greatest dimension which showed a focally irregular enhancement after the intravenous injection of iodated contrast medium (figure 1B). The whole picture was associated with significant left lung volume loss and passive atelectasis. All these findings were further analysed in more detail by means of a multiplanar reconstruction (MPR) coronal view, as shown in figure $1 \mathrm{C}$. To date, no pulmonary parenchymal nodules, adenopaties or pericardial effusion were seen to be suggesting the disease to be confined to the pleura. Brain and abdominal/pelvis CT scans showed no lesions in other sites and scintigraphy excluded any bone involvement. No endobronchial lesions were detected by means of bronchoscopy. The thoracentesis revealed a sero-sanguineous exudative effusion. Cytological examination of the pleural fluid showed a high cellularity with no evidence of malignant cells. A left video-assisted thoracoscopy for pleural biopsies was performed. Macroscopic evaluation revealed the presence of small firm nodules on the parietal pleura while the visceral one and the lung parenchyma were normal. Light microscopy examination of the pleural tumour showed both fragments of dense fibrosis tissue with infiltration of mononuclear cells and fragments of soft and well vascularised fibrosis. The tumour displayed a myxoid/chondromyxoid stroma organised in a nodular pattern and infiltrated by short strands or solid nests of medium-small size tumour cells. The majority of these cells had a polarised cytoplasm, in many instances with erythrocytes-containing intracellular vacuoles, and bland and clear nuclei with small nucleoli (figure 2A-2B). No necrosis and a very low mitotic activity $(<1 / 10 \mathrm{HPF})$ were observed (figure $2 \mathrm{C}$ ). Additional and scarce multinucleated cells appearing as histiocytoid cells were also present. Tumour cells showed immunereactivity for vimentin (figure 2D) while stainings for calretinin and cytokeratins 5/6 were negative (figure 2E-2F). Staining for thyroid transcription factor 1, and oestrogen and progesterone receptors were also negative (data not shown). Conversely, tumour cells showed immune-reactivity for CD31, CD34, factor VIII and ulex europeaus (figure 3A3D). A diagnosis highly suggestive of unilateral primary PEH was made on the basis of the radiographic, histological and immune-histochemical findings. The patient refused any treatment and left the hospital: she died in her own home three months later due to the onset of acute and progressive respiratory failure.

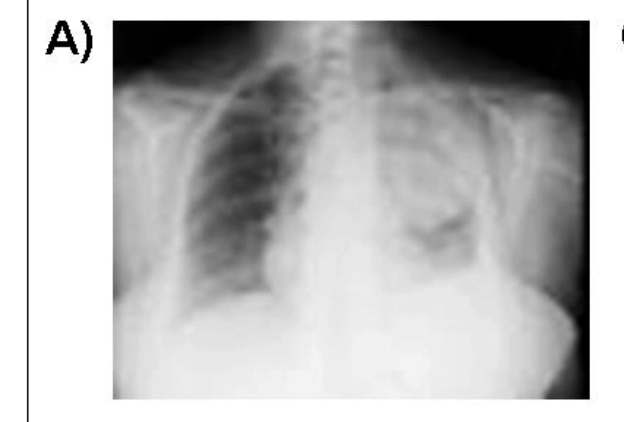

B)
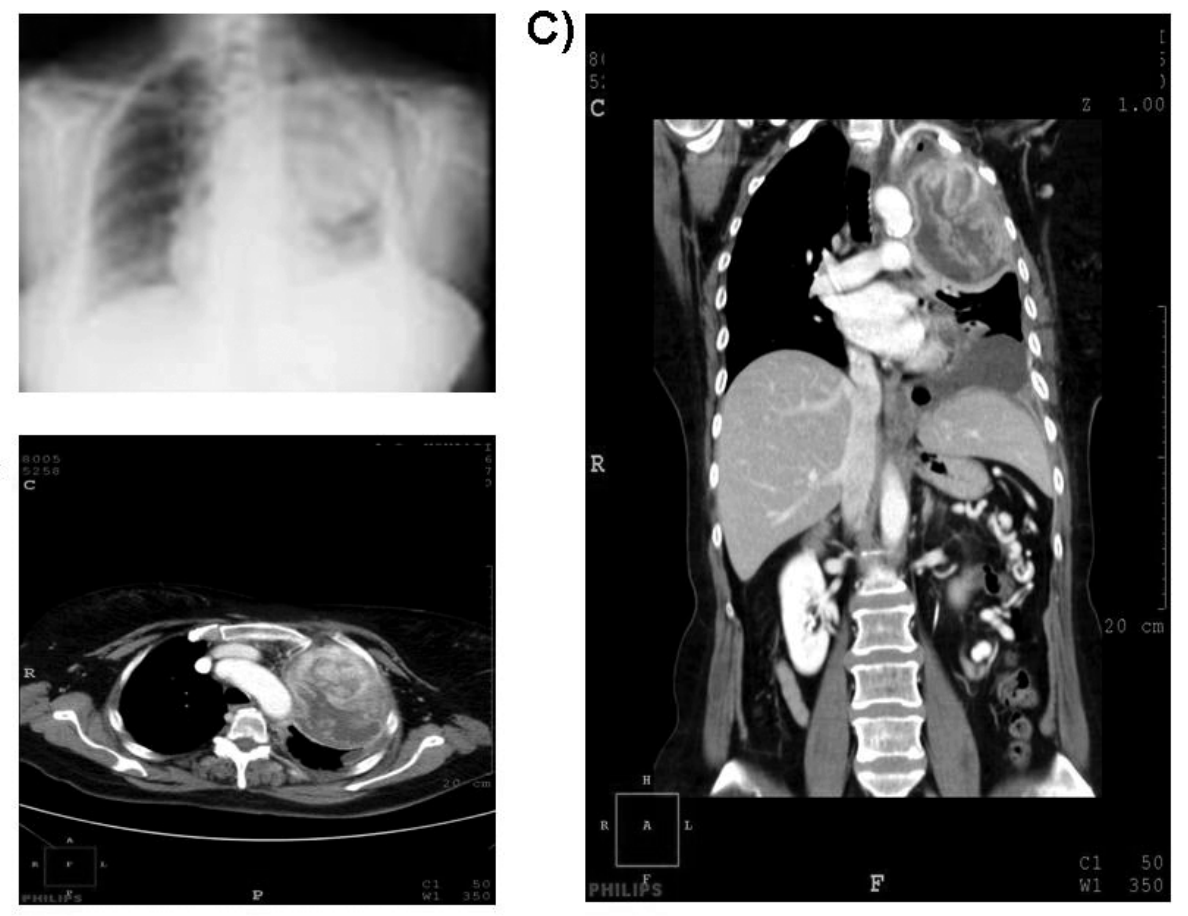

Fig. 1. - Standard chest $\mathrm{X}$ ray showing a large-size mass occupying the upper and middle fields of the left hemitho$\operatorname{rax}(\mathrm{A})$. Axial MDCT scan of the thorax showing a lobulated large-size solid lesion with in-homegeneous contrast enhancement after i.v. administration of iodinated medium (B). In C, coronal MPR allowed a better anatomical definition of the lesion with no evidence of local infiltration. Passive lamellar atelectasis and evidence of omolateral basal pleural effusion. 


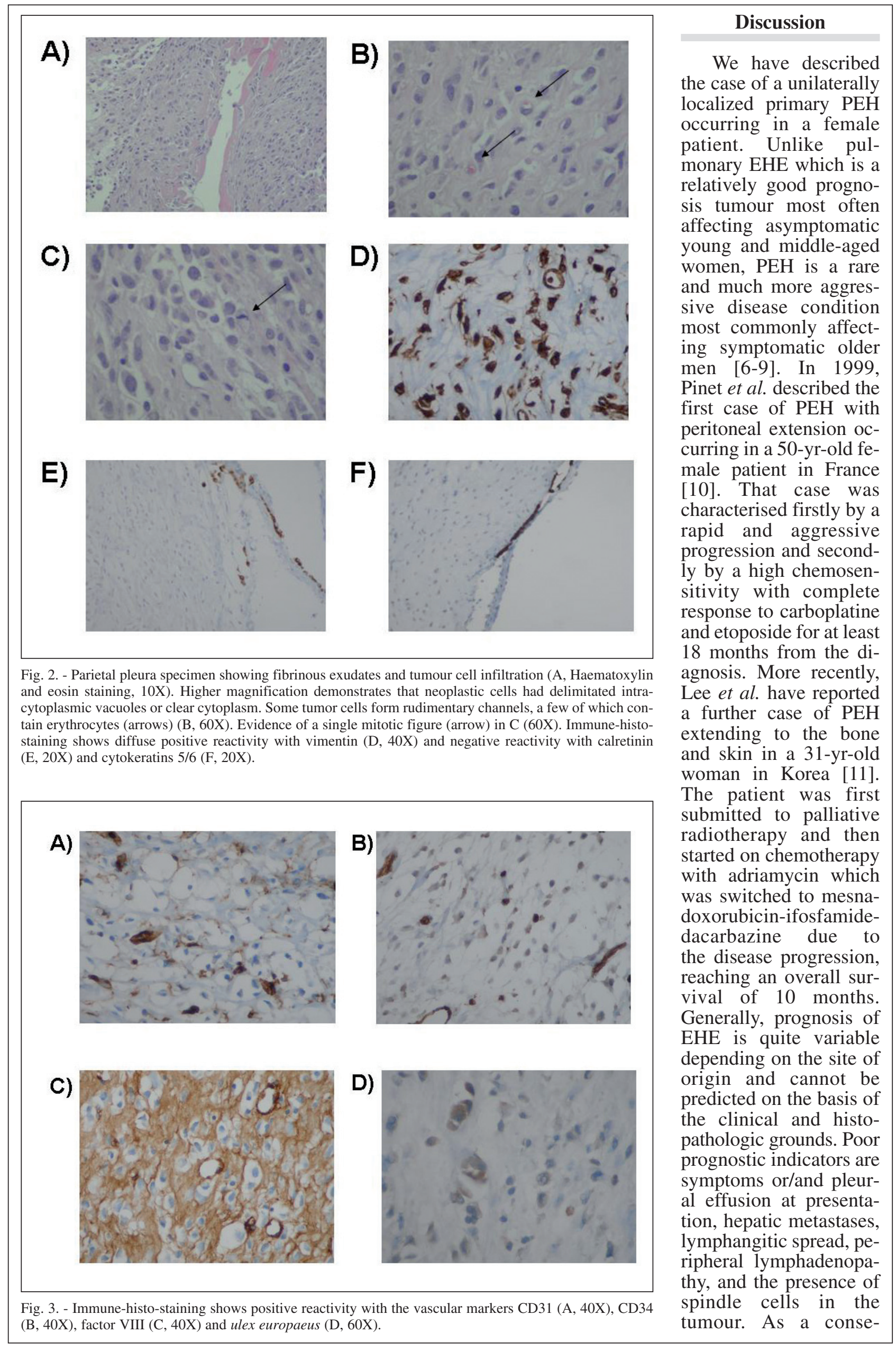


quence, differentiation of PEH from the pulmonary counterpart is an issue of concern as prognosis and treatment are different. Differentiation from mesothelioma is also important due to clinical and radiographic similarities. Additional conditions that have to be taken into consideration are the most common presentation of metastatic adenocarcinoma and the extremely rare occurrence of primary pleural epitheliod angiosarcoma. Diagnosis of EHE is suspected on histology and confirmed by immunohistochemistry. Indeed, presentation on radiology (that is, pleural effusion and thickening) may be highly overlapping. EHE is characterised by short strands and solid nests of tumour cells in a hyaline or myxoid stroma. Wellformed small vessels and multiple intracellular vacuoles are also present. An inflammatory reaction may be seen occasionally. A "rhabdoid" phenotype has also been described [12]. Positive stains with anti-vimentin, anti-CD31/CD34 and anti-Factor VIII/BNH9 antibodies highly indicate the vascular nature of the tumour. To date, the anti-factor VIII/BNH9 stains identify respectively highly differentiated and undifferentiated tumour cells of endothelial origin. Conversely, negativity of anti-cytokeratins staining excludes tumours of epithelial origin, despite a weak positivity has been reported to occur also in EHE [13]. A low mitotic index and the lack of intracellular mucin-containing vacuoles are also helpful discriminating features. Further negativity for the mesenchimal differentiation marker, calretinin, excludes mesothelioma. Lastly, distinguishing PEH from angiosarcoma is instead much more challenging due to morphological and immunohistochemical overlaps because of their common derivation [12].
The distinction of PHE from epitheliod angiosarcoma has not been well addressed in previous reports. However, higher nuclear/cytoplasm ratios, atypical nuclear features, highly pleomorphic epitheliod cells with abundant red cells containing vacuoles and necrosis are more suggestive for the latter. Additional conditions to be considered are the primary fibrous tumour and the desmoids tumour of the pleura that are however quite rare events. Differential diagnosis of PHE by way of clinical and radiological features is summarised in table 1. In addition, distinctive immune-histochemistry patterns are reported in table 2 .

In conclusion, the current report represents the third case of a primary PHE occurring in a middleaged female patient, whose diagnosis was confirmed by immune-histo-chemistry. The patient was symptomatic at presentation with a radiological picture indicative of pleural thickening and effusion in association with a large-size pleural mass. No adenopathies and metastases were found suggesting that the tumour was localised and likely less aggressive than others reported in the literature. Unfortunately, this was not the case as the patient died soon after having refused any treatment. In this issue, although in asymptomatic patients no therapy is considered, curative surgical resection is actually the treatment of choice when applicable. Lung transplantation should be considered in patients with vascular aggressivity and pleural hemorrhagic effusion [14]. Various chemotherapeutic agents, including alpha-interferon and radiation therapy regimens have been used alone or in conjunction with surgery; however no demonstrable therapeutic benefit has been described to date $[1,2,9,10]$. Despite this being a

Table 1. - Clinical and radiological differential diagnosis of EHE

\begin{tabular}{|c|c|c|c|c|c|c|c|}
\hline & PHE & $\begin{array}{l}\text { Pulmonary } \\
\text { EHE }\end{array}$ & $\begin{array}{c}\text { Pleural } \\
\text { angiosarcoma }\end{array}$ & Mesothelioma A & Adenocarcinoma & $\begin{array}{c}\text { Primary } \\
\text { fibrous tumor } \\
\text { of the pleura }\end{array}$ & $\begin{array}{l}\text { Desmoid } \\
\text { tumor } \\
\text { of the pleura }\end{array}$ \\
\hline Sex predominance & M & $\mathrm{F}$ & M & M & M & M (malignant disease) & no \\
\hline Age & older & young & middle-older & older & middle-older & older & middle \\
\hline Asbestos exposure & $+/-$ & infrequent & rare & +++ & - & - & - \\
\hline $\begin{array}{l}\text { Clinical } \\
\text { presentation }\end{array}$ & $\begin{array}{l}\text { dyspnoea, cough, } \\
\text { chest pain }\end{array}$ & asymptomatic & $\begin{array}{l}\text { asymptomatic, } \\
\text { chest pain }\end{array}$ & chest pain & chest pain & $\begin{array}{c}\text { asymptomatic } \\
\text { dyspnoea and cough }\end{array}$ & $\begin{array}{l}\text { chest pain, } \\
\text { dyspnoea }\end{array}$ \\
\hline $\begin{array}{l}\text { X-ray lesion } \\
\text { appearance }\end{array}$ & $\begin{array}{l}\text { multiple nodular } \\
\text { plaques }\end{array}$ & $\begin{array}{l}\text { multiple nodular } \\
\text { plaques }\end{array}$ & $\begin{array}{l}\text { multifocal } \\
\text { and diffuse }\end{array}$ & $\begin{array}{l}\text { multifocal } \\
\text { and diffuse }\end{array}$ & focal & focal & focal \\
\hline $\begin{array}{l}\text { Lesion } \\
\text { distribution }\end{array}$ & $\begin{array}{c}\text { unilateral } \\
\text { (right predominance) }\end{array}$ & bilateral & unilateral & $\begin{array}{c}\text { unilateral } \\
\text { (most frequently) }\end{array}$ & unilateral & unilateral & unilateral \\
\hline $\begin{array}{l}\text { Associated } \\
\text { adenopathies }\end{array}$ & infrequent & rare & yes & yes & yes & no & no \\
\hline $\begin{array}{l}\text { Pleural thickening } \\
\text { and effusion }\end{array}$ & frequent & infrequent & yes & yes & pleural effusion & no & no \\
\hline Metastasis & rare & rare & rare & yes (advanced disease) & yes & no & rare \\
\hline
\end{tabular}


Table 2. - Differential diagnosis of EHE by immune-histo-chemistry

\begin{tabular}{|c|c|c|c|c|c|}
\hline EHE & $\begin{array}{c}\text { Epitheliod } \\
\text { angiosarcoma }\end{array}$ & Mesothelioma & Adenocarcinoma & $\begin{array}{c}\text { Primary fibrous } \\
\text { tumor } \\
\text { of the pleura }\end{array}$ & $\begin{array}{l}\text { Desmoid tumor } \\
\text { of the pleura }\end{array}$ \\
\hline $\begin{array}{l}\text { CD31+, CD34+, } \\
\text { Factor VIII+, } \\
\text { CK+/- } \\
\text { Ki67 + }\end{array}$ & $\begin{array}{c}\text { CD31+, CD34+, } \\
\text { Factor VIII+, } \\
\text { CK+/- } \\
\text { Ki67 +++ }\end{array}$ & $\begin{array}{c}\text { Calretinin }+, \\
\text { vimentin+, CK 5/6+, } \\
\text { WT1+ } \\
\text { Ki67++/+++ }\end{array}$ & $\begin{array}{c}\text { CK+, TTF-1+, } \\
\text { Ki67+++ } \\
\text { CEA+, mucins+ }\end{array}$ & $\begin{array}{c}\text { CD34+, CD99+, } \\
\text { Bcl-2+, EMA+, } \\
\text { vimentin+ } \\
\text { Ki67 +/- }\end{array}$ & $\begin{array}{l}\text { Vimentin+, smooth } \\
\text { muscle actin+, } \\
\text { desmin+, } \\
\text { S100 - } \\
\text { Ki67 - }\end{array}$ \\
\hline
\end{tabular}

limitation of this report as no information on therapy response can be provided, we believe that reporting new cases of rare disease conditions are of interest for the scientific community as they provide evidence for improving their management in clinical practice.

\section{References}

1. Dail D, Liebow A. Intravascular bronchioloalveolar tumor. Am J Pathol 1975; 78: 6A.

2. Kitaichi M, Nagai S, Nishimura K, et al. Pulmonary epithelioid haemangioendothelioma in 21 patients, including three with partial spontaneous regression. Eur Respir J 1998; 12: 89-96.

3. Einsfelder B, Kuhnen C. Epithelioid hemangioendothelioma of the lung (IVBAT) - clinicopathological and immunohistochemical analysis of 11 cases. Pathologe 2006; 27: 106-15.

4. Coulibaly B, Tasei AM, Payan-Defais MJ, et al. Pulmonary epithelioid haemangioendothelioma: two different clinical courses. Rev Mal Respir 2008; 25: 867-870.

5. Sakamoto N, Adachi S, Monzawa S, et al. High resolution CT findings of pulmonary epithelioid hemangioendothelioma: unusual manifestations in 2 cases. J Thorac Imaging 2005; 20: 236-238.

6. Yousem SA, Hochholzer L. Unusual thoracic manifestations of epithelioid hemangioendothelioma. Arch Pathol Lab Med 1987; 111: 459-463.
7. Lin BT, Colby T, Gown AM, et al. Malignant vascular tumors of the serous membranes mimicking mesothelioma. A report of 14 cases. Am J Surg Pathol 1996; 20: 1431-1439.

8. Crotty EJ, McAdams HP, Erasmus JJ, et al. Pithelioid hemangioendothelioma of the pleura: clinical and radiologic features. Am J Roentgenol 2000; 175: 15451549.

9. Al-Shraim M, Mahboub B, Neligan PC, et al. Primary pleural epithelioid haemangioendothelioma with metastases to the skin. A case report and literature review. $J$ Clin Pathol 2005; 58: 107-109.

10. Pinet C, Magnan A, Garbe L, et al. Aggressive form of pleural epithelioid haemangioendothelioma: complete response after chemotherapy. Eur Respir J 1999; 14: 237-238.

11. Lee YJ, Chung MJ, Jeong KC, et al. Pleural epithelioid hemangioendothelioma. Yonsei Med J 2008; 49: 10361040.

12. Saqi A, Nisbet L, Gagneja P, et al. Primary pleural epithelioid hemangioendothelioma with rhabdoid phenotype: report and review of the literature. Diagn Cytopathol 2007; 35: 203-208.

13. Gray MH, Rosenberg AE, Dickersin GR, et al. Cytokeratin expression in epithelioid vascular neoplasms. Hum Pathol 1990; 21: 212-217.

14. Bagan P, Hassan M, Le Pimpec Barthes F, et al. Prognostic factors and surgical indications of pulmonary epithelioid hemangioendothelioma: a review of the literature. Ann Thorac Surg 2006; 82: 2010-2013.

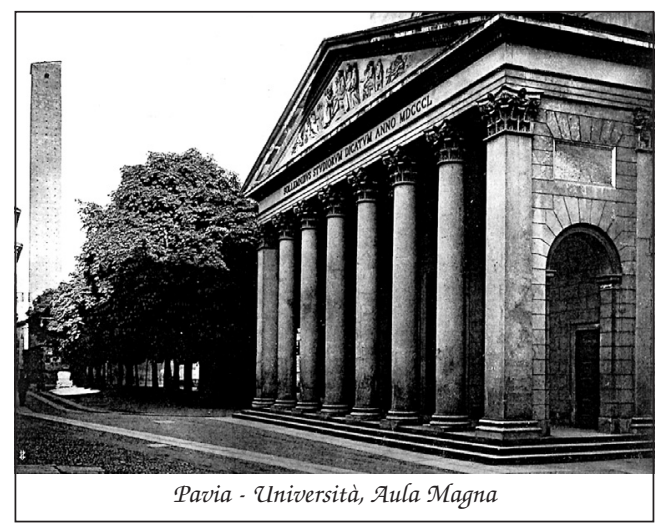

